\title{
International Research Progress and Evolution Trend of Interpersonal Trust-Prospects under COVID-19 Pandemic
}

\author{
Bin $\mathrm{Ji}^{1}$ and Ruyin Long ${ }^{2,3, *}$ \\ 1 School of Economics and Management, China University of Mining and Technology, Xuzhou 221116, China; \\ binji1994111@163.com \\ 2 The Institute for Jiangnan Culture, Jiangnan University, Wuxi 214122, China \\ 3 School of Business, Jiangnan University, Wuxi 214122, China \\ * Correspondence: longruyin@163.com
}

check for updates

Citation: Ji, B.; Long, R.

International Research Progress and

Evolution Trend of Interpersonal

Trust-Prospects under COVID-19

Pandemic. Sustainability 2022, 14, 987

https://doi.org/10.3390/su14020987

Academic Editor: João Carlos

Correia Leitão

Received: 30 November 2021

Accepted: 4 January 2022

Published: 17 January 2022

Publisher's Note: MDPI stays neutral with regard to jurisdictional claims in published maps and institutional affiliations.

Copyright: (C) 2022 by the authors. Licensee MDPI, Basel, Switzerland. This article is an open access article distributed under the terms and conditions of the Creative Commons Attribution (CC BY) license (https:/ / creativecommons.org/licenses/by/ $4.0 /)$.

\begin{abstract}
Retrospecting articles on interpersonal trust is of great importance for understanding its current status and future development in the context of the COVID-19 pandemic, especially, with the widespread use of Big Data and Blockchain. In total, 1532 articles related to interpersonal trust were collected as research database to draw keyword co-occurrence mapping and timeline mapping by VOSviewer and CiteSpace. On this basis, the research content and evolution trend of interpersonal trust were systematically analyzed. The results show that: (1) Data cleaning by code was first integrated with Knowledge Mapping and then used to review the research of interpersonal trust; (2) Developed countries have contributed the most to the research of interpersonal trust; (3) Social capital, knowledge sharing, job and organizational performance, Chinese Guanxi are the research hotspots of interpersonal trust; (4) The research hotspots on interpersonal trust evolve from the level of individual psychology and behavior to the level of social stability and development and then to the level of organization operation and management; (5) At present, the research on interpersonal trust is in the outbreak period; fMRI technology and Big Data and Blockchain technology gradually become vital research tools of interpersonal trust, which provides significant prospects for the following research of interpersonal trust under the COVID-19 pandemic.
\end{abstract}

Keywords: interpersonal trust; evolution trend; co-occurrence analysis; cluster analysis

\section{Introduction}

As an important basis for interpersonal communication and association, interpersonal trust is a significant guarantee for inter-organizational and organizational negotiation and cooperation, a vital factor affecting organizational performance, and a crucial indicator to measure the harmonious and stable development of society. In the mid-19th century, Deutsch started the research of interpersonal trust when conducting a prisoner's dilemma experiment, and found "interpersonal trust" as the disadvantage of something that does not happen as expected and may outweigh the benefit of wishing to happen [1]. Then, Rotter developed the Interpersonal Trust Scale (ITS), which inspired scholars to think about the dimensions of interpersonal trust and fostered their interest in measuring the scale [2]. At the end of 20th century, with economic globalization and organizational socialization, the research on interpersonal trust entered a period of theoretical explosion. Scholars began to systematically study the influencing factors and effects of interpersonal trust, and put forward development stage theory, rational choice theory, social system theory (social structure and social culture theory), etc., which laid a solid foundation for the following research. Since the 21st century, with economic development and social stability becoming important concerns, interpersonal trust at the organizational level and social level has received increasing attention. Scholars have focused on the role of interpersonal trust on organizational citizenship behavior, management practice, and organizational performance [3], and the role of interpersonal trust between organizations 
on communication, negotiation, contract signing [4,5]. They linked interpersonal trust with social institution and culture, meanwhile believing that social norms, culture, values interact with interpersonal trust [6]. In addition, the outbreak of public crises such as financial crises, hurricanes, and pandemic has led to the research development on trust in the field of public crises. However, scholars paid attention mainly to the role of generalized trust (social trust) and political trust in public crisis management [7], ignoring the fact that interpersonal trust is the basis of generalized trust and political trust. Moreover, COVID-19 further highlights that interpersonal trust is an invisible power resolving social risks, since it has a positive impact on alleviating negative emotions and participating in rescue operations [8].

Existing studies provide extensive research on trust between different roles, such as doctor-patient trust, consumer trust, and interpersonal trust within the organization. Those research constructed a theoretical framework centered on personality trait theory, human relations theory, rational decision theory, social system theory, enriched the definition and characteristics of interpersonal trust, clarified the influence of factors such as individual characteristics, interpersonal style, values, risk perception, social support, social culture, institutions, solved the problem of measuring interpersonal trust between different roles and different regions, and verified the vital effect of interpersonal trust on individual psychology and behavior, organization operation and management, social stability and development.

However, there are still some problems and challenges, which are mainly reflected in the following: (1) There is less research on interpersonal trust, and the topics are mostly about trust and organizational trust [5]; (2) There are many definitions of interpersonal trust, but there is a relative lack of summary [4]; (3) There is a lack of the use of scientific measurement methods; (4) The research perspective needs to be broadened, and there is a lack of backgrounds such as COVID-19 pandemic and digital governance.

The bibliometrics was used to effectively avoid the cognitive bias caused by subjective judgments to a certain extent. After summarizing the basic situation of the research on interpersonal trust, it was found that the theoretical literature and hot topics of the research on interpersonal trust, and the definition and hot topics were summarized according to the three levels of individual, organization, and society, presenting the development clue of the research on interpersonal trust, filling up the gaps of interpersonal trust in recent years, enriching the theoretical basis of interpersonal trust in public crisis response, providing valuable references for the use of digital technologies such as big data and blockchain to conduct research on interpersonal trust in the context of the COVID-19 pandemic.

\section{Materials and Methods}

\subsection{Data Resources}

Since WoS is the most extensive database covering the field of social sciences, this study took WoS as the retrieval source. In the core collection, TS = " personal trust" or "interpersonal trust" or "inter-personal trust" or "interpersonal trust") and DT = ("article" or "review") not PY = 2021 were input, and "SCI-EXPANDED" and "SSCI" were set as citation index. As a result, a total of 1780 articles from 1956 to 2020 were retrieved by 18 January 2021. As the existing bibliometric software cannot identify the trust articles with the relevant meanings of "monopoly" belonging to "trust", this study used Eclipse, an extensible development platform based on the Java environment, to write codes to process data. After reading a large number of articles, this study established an "irrelevant word database on interpersonal trust "containing 24 irrelevant words, which was used as the rules for deleting irrelevant articles. Finally, 1532 articles were selected from the 1780 articles during the period of 1956 to 2020.

\subsection{Method}

Co-occurrence analysis is a method to measure the frequency of co-occurrence of paired words in different articles. The keywords are usually the highly condensed expres- 
sions, and thus can to a certain extent represent the research theme of the article, and reflect its central idea. Bibexcel is a document metering software, which can preprocess data such as text merging and duplication removing [9]. Therefore, Bibexcel was used in this study to extract and analyze the fields of countries or regions, authors, keywords, references in the articles related to interpersonal trust.

Cluster analysis is a method to categorize samples one by one and cluster them into a small classification unit to intuitively show differences and connections of categorized objects (individuals, indicators). VOSviewer is a knowledge mapping software with functions of co-occurrence analysis, co-citation analysis, etc. Nodes of different categories and lines between nodes are marked in different colors, which can clearly show the connections among nodes in the co-occurrence mapping. CiteSpace is a mainstream social network analysis software. Similar to VOSviewer, CiteSpace can also conduct knowledge unit analysis [10]. Most importantly, the timeline mapping it contains takes the year as the horizontal axis, and uses the color of the line between nodes to reflect the time clue, which can clearly and effectively present the evolution trend of the research themes. Therefore, this study respectively used VOSviewer and CiteSpace to draw the co-occurrence mapping and timeline map of keywords so as to analyze the hotspots and evolution trend of interpersonal trust.

\section{Results}

\subsection{Articles Publication Status}

According to the selected 1532 articles, this study drew the graph of annual publication number, cumulative publication number and growth rule of interpersonal trust (see Figure 1).

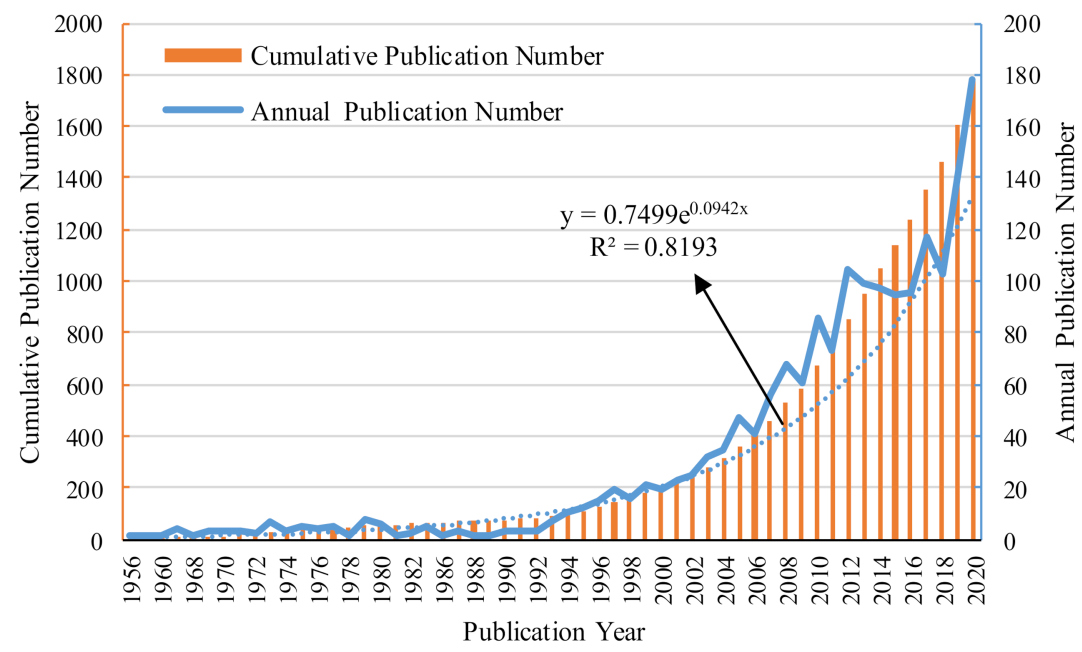

Figure 1. Article publication status.

As is shown in Figure 1, in 1956, the WoS Core Collection began to include articles related to interpersonal trust. From 1956 to 1989, the annual publication number of interpersonal trust was fluctuating, with an average annual publication number of only 2. After 1990, the annual publication number generally displayed an increasing trend. According to the index fitting curve of annual publication number, $\mathrm{y}=0.7499 \mathrm{e}^{0.1069 x}, \mathrm{R}^{2}=0.8193$. After the year 2000, research on interpersonal trust entered a period of explosive growth; especially since 2018, the annual publication number has been rising almost linearly.

\subsection{Country or Region and Institution Publication Status}

To a certain extent, the number of articles reflects the contribution of the country or region to the research of interpersonal trust. Table 1 lists the top 10 countries or regions and institutions that published articles on interpersonal trust from 1956 to 2020. According to statistics, 81 countries or regions have conducted research on interpersonal trust. Among 
them, the United States has published the most, with a total of 758 articles published, accounting for $42.58 \%$, indicating that the United States takes a leading position in research on interpersonal trust. China ranks the second on the publication list with 252 articles published, accounting for $14.16 \%$. The main reason for the large gap between the United States and China is that the study of interpersonal trust in China started late. Then Britain, Germany, Canada, The Netherlands, Australia and other developed countries follow on the list. In addition, 8 of the top 10 high publication institutions are all in the United States, and the remaining are Vrije University Amsterdam in The Netherlands and the City University of Hong Kong in China. In short, with the exception of China, the largest developing country, the current main research institutions in the field of interpersonal trust come from developed countries.

Table 1. Top 10 countries/regions and institutions publication status.

\begin{tabular}{cccc}
\hline & \multicolumn{2}{c}{ High Publication Countries } & \multicolumn{2}{c}{ High Publication Institution } \\
\cline { 2 - 3 } Rank & Country/Region & Number (\%) & Institution \\
\hline 1 & US & $758(42.58)$ & University of Minnesota \\
2 & China & $252(14.16)$ & Vrije University Amsterdam $(1.40)$ \\
3 & UK & $173(9.72)$ & City University of Hong Kong \\
4 & Germany & $124(6.97)$ & University of Wisconsin \\
5 & Canada & $103(5.79)$ & Northwestern University \\
6 & The Netherlands & $103(5.79)$ & University of Michigan \\
7 & Australia & $100(5.62)$ & Harvard University \\
8 & Spain & $59(3.32)$ & Michigan State University \\
9 & South Korea & $58(3.26)$ & University of Amsterdam \\
10 & Swedish & $41(2.30)$ & Georgia State University \\
\hline
\end{tabular}

\subsection{Co-Citation Analysis}

High citation analysis can explain which researchers have made great contributions to the research of interpersonal trust, thus helping understand their specific contributions and breakthroughs. According to co-citation analysis of authors and articles via Bibwxcel, the author's cited frequency and their most cited articles were obtained. Table 2 only lists the top 20 most cited authors, citation frequency and their research content.

By analyzing the most cited article of the most cited author, this study found these most cited authors are all the founders of theories related to interpersonal trust or pioneers in subdivision fields. This study summarized the top 20 most cited authors and their research content from the perspectives of individual, organization and society level.

At the individual level, Deutsch was the first social psychologist to use an experimental method to define interpersonal trust. He believed that the generation of interpersonal trust may not necessarily be related to interests; in other words, it may not be caused by rational choice [1]. Mayer and Rotter were representatives of the personality theory. Rotter was one of the first scholars to discuss interpersonal trust as a form of personality, and developed the Interpersonal Trust Scale (ITS). He suspected a trustworthy person had the advantages of humor and popularity [2]. Mayer proposed a comprehensive model of interpersonal trust. On the one hand, he considered interpersonal trust was affected by the internal tendency of the truster, such as development experience, personality type, and cultural background; on the other hand, he thought interpersonal trust was affected by the competence, goodwill and integrity of the trustee [11]. Lewicki contributed to the research of psychologists on interpersonal relationships, and explored the dynamic development of the establishment, decline and restoration of trust, which laid the foundation for the restoration research of interpersonal trust [13]. Based on the two-dimensional structure of cognitive trust and affective trust, McAllister reckoned that demographic characteristics, experience and competence had an impact on cognitive trust, and altruism and the frequency of interaction had an impact on affective trust [18]. Lewis deemed interpersonal trust was a typical social reality, which not only existed in the cognition and affection of 
the individually psychological level, but also reflected the institutional structure of the society [26]. Based on the existing Interpersonal Trust Scale, Butler developed Conditions of Trust Inventory (CTI) which included 10 dimensions, namely, availability, competence, consistency, discreetness, fairness, integrity, loyalty, openness, promises fulfillment, and receptivity [27]. Both Williamson and Hardin were representatives of rational decisionmaking theory. Williamson gave the definition of calculative trust, thinking it contained risk. According to Williamson, calculation of trust was rational like institutional trust, and could be analyzed by cost-benefit. On the contrary, personal trust focused on interpersonal communication and did not contain calculative elements [20]. Hardin analyzed the Bayesian trust model from the epistemology of trust. In his opinion, the role of experience learning in risk reduction and the restraining ability of sanctions in trust should be considered [28].

Table 2. Top 20 most cited authors and their research content.

\begin{tabular}{|c|c|c|c|c|}
\hline Rank & Author & Citation Frequency & Published Year & Content \\
\hline 1 & Rotter JB [2] & 789 & 1967 & Interpersonal Trust Scale \\
\hline 2 & Mayer RC [11] & 666 & 1995 & Dimensions of interpersonal trust \\
\hline 3 & Putnam RD [12] & 600 & 1994 & Trust and social capital \\
\hline 4 & Lewicki RJ [13] & 587 & 1996 & $\begin{array}{c}\text { A review of different disciplines of } \\
\text { interpersonal trust }\end{array}$ \\
\hline 5 & Rousseau DM [14] & 432 & 1998 & $\begin{array}{l}\text { A review of interpersonal trust in } \\
\text { organization and between organizations }\end{array}$ \\
\hline 6 & Dirks KT [15] & 411 & 2002 & Meta-analysis of leadership trust \\
\hline 7 & Kramer RM [16] & 392 & 1998 & $\begin{array}{l}\text { How to strengthen interpersonal trust in } \\
\text { an organization }\end{array}$ \\
\hline 8 & McKnight DH [17] & 382 & 2002 & Consumer trust in electronic commerce \\
\hline 9 & McAllister DJ [18] & 363 & 1995 & $\begin{array}{l}\text { Measurement of interpersonal trust } \\
\text { within an organization }\end{array}$ \\
\hline 10 & Deutsch M [1] & 317 & 1958 & The definition of interpersonal trust \\
\hline 11 & Zaheer A [19] & 311 & 1998 & $\begin{array}{c}\text { The influence of inter-organizational trust } \\
\text { and interpersonal trust on } \\
\text { organizational Performance }\end{array}$ \\
\hline 12 & Williamson OE [20] & 305 & 1993 & $\begin{array}{l}\text { Rational decision making of } \\
\text { interpersonal trust }\end{array}$ \\
\hline 13 & Yamagishi T [21] & 297 & 1994 & Cross-cultural comparison of general trust \\
\hline 14 & Coleman J [22] & 287 & 1994 & Relation of trust and social capital \\
\hline 15 & Luhmann N [23] & 285 & 1979 & The social function of trust \\
\hline 16 & Gefen D [24] & 276 & 2002 & $\begin{array}{l}\text { Consumer trust under } \\
\text { electronic commerce }\end{array}$ \\
\hline 17 & Fukuyama F [25] & 268 & 1995 & The social function of trust \\
\hline 18 & Lewis JD [26] & 222 & 1985 & The social function of trust \\
\hline 19 & Butler J [27] & 222 & 1991 & Conditions of Trust Inventory \\
\hline 20 & Hardin R [28] & 218 & 1993 & Bayesian trust model \\
\hline
\end{tabular}

At the organization level, Rousseau and Lewicki both reviewed the development of interpersonal trust, both of them were representatives of the theory of human relations. Rousseau discussed the definition, function, type and other issues of organizational and inter-organizational trust from different disciplinary perspectives, and believed it was necessary to discuss interpersonal trust at different levels [14]. Dirks used meta-analysis to review trust in leader, summarizing the antecedent variables of trust in leader, such as leadership styles, participation in decision making, procedural justice, as well as outcome variables, like work attitude, job performance, and turnover intention [15]. Kramer regarded interpersonal trust in organization as a psychological state and choice behavior, and maintained that it supported transaction costs, spontaneous social skills and voluntary obedience, while suspicion, surveillance and psychological contract violations would destroy interpersonal trust [16]. Both McKnight and Gefen studied interpersonal trust under e-commerce. McKnight proposed a consumer trust model that included trust tendency, 
institutional trust, trust belief and trust intention [17]. Gefen constructed a consumer trust scale under e-commerce, and reckoned the supplier's competence had a greater impact on customer trust when shopping in real stores, while the supplier's integrity and goodwill had a greater impact on customer trust when shopping online [24]. Zaheer analyzed the role of trust in exchanges between enterprises at the individual and organization levels, and regarded inter-organizational trust as the main driving factor of exchange performance, negotiation and conflict, while interpersonal trust had little direct influence on these results [19].

At the society level, Coleman and Putnam were representatives of social structure theory. Coleman reckoned trust was an important part of social capital, and believed that trust was a media of social relationship in the social exchange system [22]. Putnam put forward the three main components of social capital, namely, trust, social norms and relationship network [12]. Yamagishi couple were representatives of cross-cultural studies. They used commitment and social uncertainty to explain the difference in trust level between the United States and Japan. They concluded that Americans generally had a higher level of trust than Japanese, and speculated that interpersonal trust could help people get rid of the relation of mutual commitment which could alleviate social uncertainty to a certain extent [21]. Luhmann and Fukuyama were both representatives of social culture theory. Luhmann observed that the complexity of interpersonal activities was the root cause of social complexity, but trust was a mechanism to reduce social complexity [23]. Fukuyama considered that the trust level of a country was not only related to the country's economic level, but was also inseparable from its social culture [25].

\subsection{Co-Occurrence Analysis of High-Frequency Keyword}

When extracting keywords, this study found keywords only existed in the articles published after 1993. Therefore, to effectively analyze the evolution path of research hotspots, this study adopted keywords co-occurrence analysis for articles from 1993 to 2020. According to the Bibexcel analysis results, there are 6754 keywords in 1532 articles from 1993 to 2020. Given that the existing software cannot accurately recognize the forms of words such as case, singular and plural, abbreviations and there were many original keywords, this study first formulated merging rules, and then used Eclipse to write code for merging. Specifically, words with different singular and plural numbers were first merged. For example, "virtual teams" was merged into "virtual team". Secondly, words with the same semantics but different expressions were artificially merged. For example, "interpersonal-trust" and "inter-personal trust" were unified into "interpersonal trust", and "general trust" and "generalized trust" were combined into "generalized trust". After the keywords were processed totally, 1780 keywords were obtained in this study. On the basis of the calculation formula of high-low-frequency words [29], 60 high-frequency keywords were attained at last. Table 3 lists the top 20 high-frequency keywords.

The net file and vec file generated by Bibexcel were imported into the VOSviewer, and the co-occurrence mapping of high-frequency keywords was pictured in this study (see Figure 2).

In Figure 2, keywords such as "social capital", "knowledge sharing", "performance" and "Guanxi" are close to the center with large nodes, indicating these keywords have always been important hotspots of interpersonal trust research. "Interpersonal trust" is closely related to keywords such as "organizational trust", "institutional trust", "generalized trust" and "social trust". Further research has found that "organizational trust", "institutional trust", "generalized trust" and "social trust" are the research hotspots of interpersonal trust at organization level and society level. 
Table 3. Top 20 high-frequency keywords in interpersonal trust articles.

\begin{tabular}{cccccc}
\hline Rank & Keyword & Frequency & Rank & Keyword & Frequency \\
\hline 1 & social capital & 98 & 11 & reciprocity & 19 \\
2 & trustworthiness & 43 & 12 & performance & 18 \\
3 & knowledge sharing & 37 & 13 & organizational trust & 17 \\
4 & China & 35 & 14 & personality & 16 \\
5 & cooperation & 27 & 15 & trust game & 16 \\
6 & institutional trust & 25 & 16 & risk & 15 \\
7 & social trust & 24 & 17 & satisfaction & 15 \\
8 & distrust & 24 & 19 & degotiation & 14 \\
9 & genession & culture & 13 \\
10 & virtual teams & 23 & 20 & &
\end{tabular}

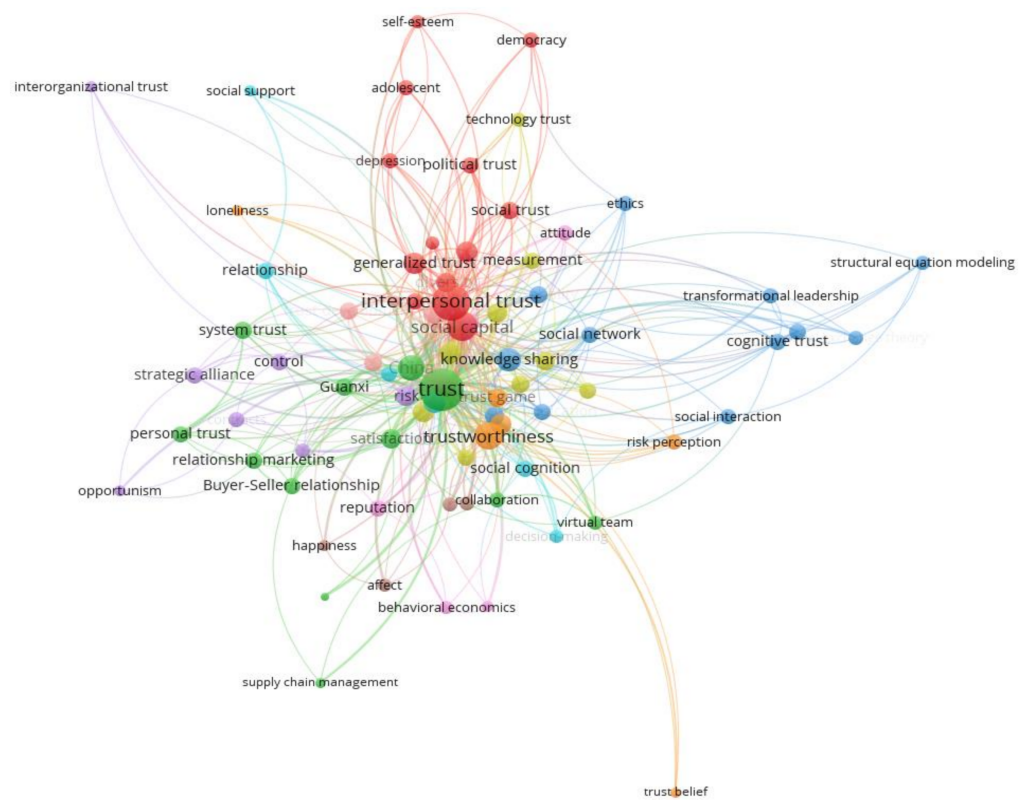

Figure 2. Co-occurrence mapping of high-frequency keywords.

In order to better understand the hotspot evolutionary trend of interpersonal trust research in recent years, and identify research frontiers, this study used CiteSpace to draw a timeline mapping of keywords from 2011 to 2020. As shown in Figure 3, there are 14 clusters, Modularity $=0.77>0.3$, Silhouette $=0.9202>0.5$, hence the clustering result is scientific. Although the cluster name is extracted from the keyword, there are situations that could not fully represent the cluster. Accordingly, this study changed the cluster name of \#9 to Chinese Guanxi after reading articles of this cluster, combined with other high-frequency keywords of this cluster. Therefore, the research hotspots of interpersonal trust in the past decade include: social capital, employees' behavior, generalized trust, trust beliefs, social support, meta-analysis, forgiveness, geological disaster, collaboration, Chinese Guanxi, knowledge management, bias, measurement, behavioral economics.

It could be seen from Figure 3 that the duration of \#12 and \#13 is relatively short, indicating that the measurement of interpersonal trust and behavioral economic research has shifted to new research branches, such as scale and meta-analysis. The clustering time of \#0,\#2, \#4 and \#5 is the longest, indicating that social capital, generalized trust, social support and meta-analysis have always been the research hotspots. Other clusters are not continuous on the time axis in recent years, indicating that the research on these hotspots has stopped or shifted. For example, \#7 "geological disasters" has turned to "food safety" and "medical and medical health incidents". 


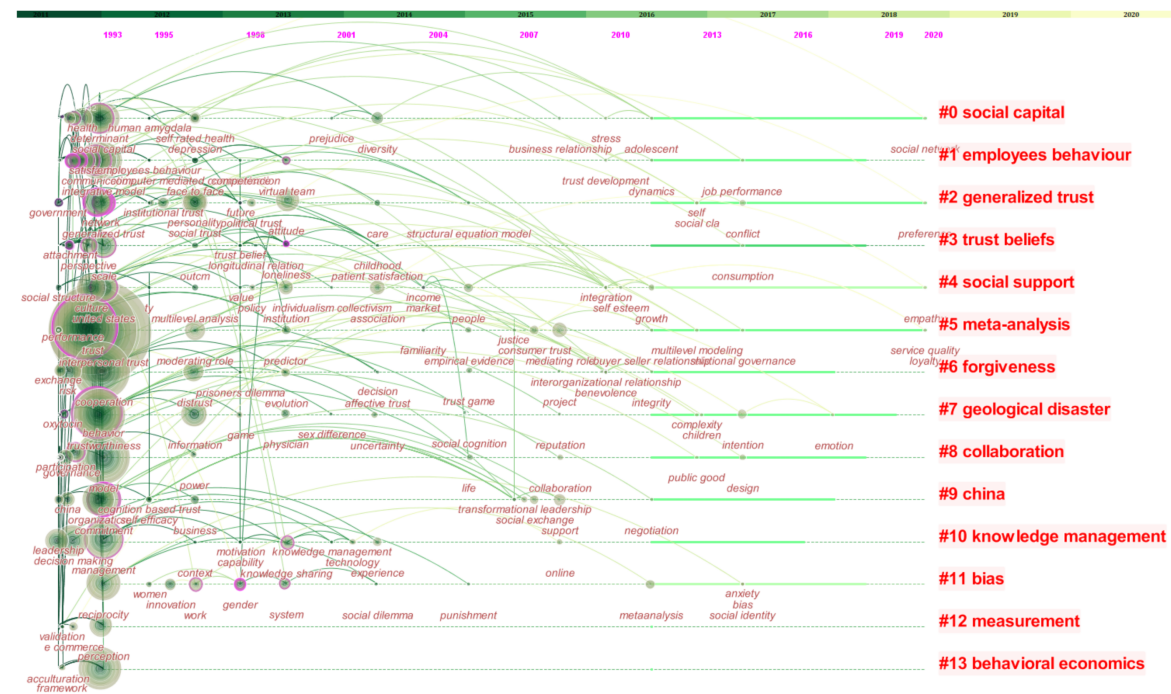

Figure 3. Timeline mapping of high-frequency keywords from 2011 to 2020.

\section{Discussion}

\subsection{Articles Structure Features}

Developed countries have contributed the most to the research of interpersonal trust. From the perspective of the publication number, the publications of the nine developed countries in Table 1 account for about $86 \%$ of the total. From the perspective of highly cited authors and literature, all most cited authors in Table 2 are from developed countries. The United States has contributed the most to the study of interpersonal trust. From the perspective of the publication number, in Table 1, the publication number of the United States accounts for about $42.58 \%$ of the total publications. From the perspective of most cited authors and articles, the 15 most cited authors are Americans in Table 2. In addition, the contribution of China, the largest developing country, to the research of interpersonal trust cannot be ignored, because China is the country with the second largest publication number.

\subsection{Clustering Analysis of High-Frequency Keywords}

In order to summarize the main research themes of interpersonal trust, this study divided the 14 clusters obtained above into 4 thematic clusters according to the high-frequency keywords and specific research content. The four thematic clusters are as follows: individual psychology and behavior, including \#3 trust beliefs, \#6 forgiveness, \#13 behavioral economics; organization operation and management, including \#1 employees' behavior, \#8 collaboration, \#9 Chinese Guanxi, \#10 knowledge management; social stability and development, including \#0 social capital, \#2 generalized trust, \#4 social support, \#7 geological disasters, \#11 bias; and research methods, including \#5 meta-analysis, \#12 measurement.

Individual psychology and behavior (\#3, \#6, \#13) mainly focuses on the influence of personality characteristics, interactive psychology and behavior of interpersonal trust, as well as the effect of interpersonal trust on individual psychology and behavior. "Trust beliefs" is often used to measure interpersonal trust, and competence, kindness and integrity are the three most representative trust beliefs [17]. In the era of Internet, scholars have also verified technical trust beliefs (function, reliability and helpfulness), interpersonal trust beliefs (competence, benevolence and integrity), and considered these two beliefs could simultaneously affect the interpersonal trust in the network, promoting the research of online interpersonal trust [30]. "Forgiveness" plays an important role in the repairing process after the destruction of trust, because apology could foster the forgiveness behavior of the trust damaged party [31]. "Behavioral economics" embodies the reciprocal purpose and economic role of interpersonal trust, the basis of rational decision making of interpersonal trust. Moreover, interpersonal trust would increase as costs decreases and benefits increases [32]. 
Organization operation and management (\#1, \#8,\#9, \#10) mainly focuses on the influence of employee and leader behavior in the organization of interpersonal trust, and the effect of interpersonal trust on organizational performance. "Employees' behavior" and "collaboration" are eternal topics of organization operation and management. The behavior of employees' dependence on leaders would significantly affect their trust in leader, which in turn affects organizational performance. Similarly, human resource practices such as cultivation of employee competence from the leader, employee dependence and rewards can apparently improve interpersonal trust and strengthen cooperation and innovative behaviors [33]. In addition, for the organizations with high interpersonal trust, the more willing the employees are to cooperate, the more positive effects they can produce. By contrast, organizations lacking interpersonal trust would suffer from the opposite effects [34]. "Knowledge management" is an important method to stimulate organizational innovation and maintain organizational competitiveness. In reality, transformational leaders could improve interpersonal trust and knowledge sharing behavior by creating a knowledge sharing atmosphere [35]. In the virtual network, organizations could enhance the social interaction of employees through online technology to establish interpersonal trust and promote the willingness to share knowledge [36]. "Chinese Guanxi", including kinship, friendship and geographical relationship, is often generated from the effective trust of Chinese people. Likewise, it has three characteristics: familiarity (intimacy), trust and mutual obligation [37], which reflect the Chinese concept of family culture and sensible society. Chinese Guanxi is considered to be an informal interaction. Face and gift, etc., not only promote interpersonal interaction, but also play a special role in decision making within the organization and negotiation between organizations. In other words, it can reduce the uncertainty of decision-making within the organization, and improve the performance of inter-organizational contracts. With the development of the politicization of organizations, Chinese Guanxi also brings some drawbacks to the development of organizations like nepotism, but the negative impact of human relations in business interaction could be alleviated to a certain extent by increasing calculative trust and weakening benevolence trust [38].

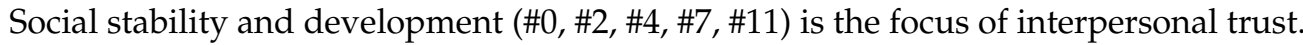
Scholars mainly discussed the influence of politics, institution and culture on interpersonal trust, as well as the positive role of interpersonal trust in improving social fairness, social cohesion and public crisis management. "Social capital" includes generalized trust or interpersonal trust, reciprocity guidelines and civic anticipation networks [17]. Social capital is the upstream social determinant of mental health, and its intervention policies could be functioned as an effective way to promote mental health and help relieve depression and stress. Meanwhile, the economic role of social capital reinforces regional communication and interaction, making it an indispensable foundation for the development of cultural and ethnic diversity [39]. In addition, the specifically social capital of company established through social responsibility activities could gain considerable economic return when the financial crisis has reduced interpersonal trust [40]. "Generalized trust" is the manifestation of interpersonal trust at the society level, which is equivalent to social trust [7]. Society with high degree of generalized trust owns better government institutions, higher economic growth and greater capacity to resolve public crises. "Social support" and interpersonal trust are good mediators of the relationship between perceived organizational politics and job satisfaction, organizational commitment, stress, and burnout. In the relationship research between doctors and patients, the effective and informative support of doctors helped patients relieve their physical and psychological burden [41]. "Geological disasters", such as tsunamis, hurricanes and earthquakes, caused tremendous damage to lives and property. The role of interpersonal trust on individual mental health made it a momentous factor in public crisis management and evaluation. Accordingly, measuring and evaluating interpersonal trust before, during and after a public crisis is conducive to crisis management. In response to public crises, people involved in public affairs would quickly form a sense of collaboration, so that interpersonal trust is to be quickly established and fostered in the recovery period of disaster [42]. During recent years, pandemics such as COVID-19 
and Ebola have led to the development of interpersonal trust in the field of public crisis. When a public health emergency broke out, authorities expanded communication channels and released comprehensive information in time, reducing the phenomenon of distrust caused by human-to-human transmission [43]. "Bias" mainly refers to the difference of interpersonal trust between men and women. In the cross-cultural research, women considerably have low trust in Thailand and Hong Kong, while in Australia, men have low trust in strangers, and women have low trust to foreigners [44]. Additionally, racial prejudice is also a political and cultural factor affecting interpersonal trust. The 2014 World View Value Survey found that white people had higher trust than black people did.

Research methods (\#5,\#12) mainly studies the scale method of interpersonal trust measurement, the game method of the influence of reciprocal preference and altruistic preference between two parties, and the meta-analysis method of summarizing variables of interpersonal trust. "Meta-analysis" is used to study the antecedents and outcome variables of interpersonal trust. Scholars used meta-analysis method to analyze the individual characteristics, such as competence, integrity and benevolence, individual behaviors in the organization, such as organizational citizenship behavior, dependent behavior and power differentiation, innovative behavior and sharing behavior. Furthermore, organizational performance, employee satisfaction and income level have always been the research content that scholars care about [45]. "Measurement" has always been a hot topic of interpersonal trust. The most commonly used scales are Interpersonal Trust Scale [2], Specific Interpersonal Trust Scale, Trust Scale, and Trust in Physician Scale. Game method is the most commonly used laboratory method. Early trust games focused on the transaction cost, gains or losses risks, finding that interpersonal trust would increase with the decrease of cost and the increase of cooperation benefits, and decrease with the increase of betrayal benefits. In recent years, transcranial Direct Current Stimulation (tDCS) and functional Magnetic Resonance Imaging (fMRI) have been introduced into the trust game to study the micro-influencing mechanism of emotion, reciprocity and interpersonal trust. It has been found that the negative influence would interrupt the trust behavior between the left temporal parietal and posterior superior temporal sulcus, and activate the activity of the anterior insula [46].

\subsection{The Evolution by Time Clues}

In order to further figure out the evolution of research hotspots by time sequence, this study first divided the research progress into four stages, then explored the evolution at every stages. In line with the statistics of publication number and the analysis of most cited authors, the total publication number from 1956 to 1989 was only 72 (see Figure 1), and the most cited articles were concentrated in 1990 to 2000 (see Table 2). Consequently, this study defined the period before 1990 as the germination stage, the period from 1990 to 2000 as the growth stage, and the period from 2001 to the present as the outbreak stage.

Germination stage (1956-1989). During this period, the research focused on fields of psychology, economics and sociology, presenting a research trend of joint development at the individual and society levels. Since Deutsch, the American social psychologist, put forward the first definition of interpersonal trust, interpersonal trust formally entered the research scope of scholars. Conceptual definitions, influencing factors and scales were the main research content of this stage.

Growth stage (1990-2000). During this period, the research scope was expanded to organizational behavior and management. Interpersonal trust developed into social trust (generalized trust) at the society level, and organizational trust (interpersonal trust within the organization) at the organization level, showing the evolution characteristics from the level of individual to society and then to organization. Scholars further promoted research on conceptual definitions, influencing factors and scales, and started research on the destruction and restoration of interpersonal trust, as well as cross-cultural research. At the individual level, some scholars maintained that interpersonal trust was a kind of prediction of whether one's own interests changed and that it underwent a dynamic development 
of establishment, development, decline and restoration [13]. Some scholars developed Trust in Physician Scale and Conditions of Trust Inventory based on the Interpersonal Trust Scale and existing research [27]. At the society level, with the emergence of population aging and social inequality, scholars begun to pay attention to the relationship between institution, economy and culture and interpersonal trust. Some scholars compared the interpersonal trust of different countries, and concluded that social culture, economy, norms and regulations were major reasons affecting interpersonal trust. Furthermore, some scholars associated social capital with trust and believed that interpersonal trust was an essential part of social capital [22,25]. At the organization level, with economic globalization and organizational socialization, scholars discovered the relationship between interpersonal trust and human resource management practices played an important role in improving corporate performance. As a result, interpersonal trust at the organization level attracted wide attention. Scholars thus found that interpersonal trust within an organization had a positive impact on goal determination, organizational performance, monitoring costs and innovative behavior.

Outbreak stage (2001-2020). During this period, the development of medical technology, such as tDCS and fMRI technology, extended the research to the field of neurology. Simultaneously, the development of computer technology, such as Big Data and Blockchain, also led the research to the fields of communication engineering and computer science. In this stage, interpersonal trust research presented the characteristics of multi-disciplinary, coordinated development at individual, organization, society levels. At the individual level, the trust game experiment has been enriched by tDCs and fMRI, and the generation and action mechanism of interpersonal trust has been studied from the neural network. At the organization level, it is believed that organizational management practices, such as knowledge sharing, job support, staff reliability and team management, were affected by interpersonal trust [35]. Additionally, the potential of Big Data and Blockchain in enhancing interpersonal trust has also been proved. Big Data and Blockchain could improve the reliability and transparency of information in information management, ensure the effective knowledge sharing, and promote trust consensus [47]. At the society level, on the one hand, scholars continued to pay attention to cross-cultural research, and maintained that the stronger organizational supervision is, the better social norms and legal systems are, the higher interpersonal trust and social trust would be. By further comparing the influence of differences in trust culture between different countries on negotiation cooperation, it was found that negotiators could avoid the influence of trust culture differences as long as they adopted strategies to improve common interests [48]. On the other hand, the role of computer technology was studied in interpersonal trust when a public crisis occurred. The analysis capabilities of Big Data and Blockchain could decrease the establishment time of trust between military and civilian and improve inter-organizational collaboration performance [49].

During the germination stage, researchers formed the personality trait theory and human relations theory. During the growth stage, researchers put forward rational decisionmaking theory, social system theory (social structure and social culture theory), and personality trait theory and human relations theory had been further developed. During the outbreak stage, researches mainly concentrated on the human relations theory and social system theory to probe the level of interpersonal trust under social events, as well as calculating the level of interpersonal trust in the laboratory.

\subsection{Limitations}

This study reviewed the basic situation, theoretical foundations and hot topics of the research on interpersonal trust, but it had the following limitations: (1) For the articles publication, we only introduced the growth trend of the number of publications, and did not specifically discuss the surge of the number. (2) For the analysis of the outbreak stage, we mainly introduced the new characteristics and hotspots of interpersonal trust research during this stage, which might have overlooked the continued development of previous 
research topics. Other researchers can: (1) read the articles in the year or period of the surge to find the realistic reasons; (2) analyze the citing articles of the highly cited articles during the outbreak stage to understand the specific development of previous research topics.

\section{Conclusions}

\subsection{Key Findings}

According to the publication number and the occurrence time of most cited articles, the research of interpersonal trust could be divided into three stages: the germination stage (1956-1989), the growth stage (1990-2000) and the outbreak stage (2001-2020). At present, interpersonal trust research is in the outbreak stage, with the publication number increasing exponentially. According to the distribution of countries or regions and research institutions, developed countries, especially the United States, have contributed the most to the research of interpersonal trust. In addition, as the largest developing country, China has made indispensable contributions to the research of interpersonal trust.

According to the analysis of most cited authors, articles and keywords, the top 20 most cited authors were the founders of theories on interpersonal trust who put forward the theory of personality traits, interpersonal relationship, rational decision-making, social system theory, or pioneers in subdivision fields who extended interpersonal trust to organizational trust, trust in leader, consumer trust and generalized trust (social trust). In the keyword co-occurrence mapping, social capital, knowledge sharing, organizational performance and Chinese Guanxi have always been significant hotspots in the research. Further research revealed that organizational trust, institutional trust, generalized trust and social trust were the research hotspots of interpersonal trust at the organization level and society level. In the timeline mapping of the past ten years, there were four research themes, namely, individual psychology and behavior, organization operation and management, social stability and development, and research methods. The theme of individual psychology and behavior mainly focused on the influence of personality characteristics, communication psychology and behavior on interpersonal trust, and the role of interpersonal trust on individual behavior. The theme of organization operation and management mainly explored the influence of employees and leadership behaviors on the organization on interpersonal trust, and the role of interpersonal trust on organizational performance. The theme of social stability and development mainly discussed the influence of politics, institution and culture on interpersonal trust, and the positive role of interpersonal trust in improving social justice, social cohesion and managing public crises. The theme of research methods mainly introduced the scale, the game and the meta-analysis method of researches of interpersonal trust.

From the perspective of evolution trend, research fields in the germination stage focused on psychology, economics and sociology. Research fields in growth stage put emphasis on organizational behavior and management. Research fields in outbreak stage were further expanded to the communication engineering and computer science, presenting characteristics of coordinated development of the individual, organization, society levels. The research themes generally displayed an evolutionary trend from individual psychology and behavior level to social stability and development level and then to organizational operation and management, and the research method theme ran through the research progress. Specifically, in the germination stage, the focus was mainly placed on the concept, influencing factors and scales of interpersonal trust at the individual level and society level. In the growth stage, scholars further improved, developed and discussed the concept, scale, influencing factors and action mechanism on the organization level. In the outbreak stage, the constantly developing science and technology has been employed to serve the cross-cultural and overall research at the individual-organization-society levels.

\subsection{Future Researches}

According to the keyword timeline mapping and the research hotspots presented during the outbreak stage, the future research can continue to study interpersonal trust 
based on organization and socialization, and specifically discuss interpersonal trust in the context of organizational environment and social events. As the main research hotspots at outbreak stage, the development of science and technology has made it a reality to analyze interpersonal trust from the micro (cellular nerve) and macro (Big Data and Blockchain integration) perspective. Hence, science and technology will be indispensable tools for the future study of interpersonal trust. Under the circumstance of public crisis of COVID-19 and integrated with the latest development of science and technology, this study presented the following three prospects.

The first is the study on the influence of Internet opinion leaders on interpersonal trust. It has been proved that online social media have played a considerable role in public opinion control during a crisis, and can serve as precisely an indispensable that affects interpersonal trust against crisis. In the future, Big Data and Blockchain can be used to further study the relationship between public trust in online authoritative media and public crisis management.

The second is the study on the dynamic and persistence of interpersonal trust. After the outbreak of the public crisis, it was found that interpersonal trust would increase in some places, but no concrete efforts have been made to verify whether interpersonal trust in these places has been restored to the level before the outbreak of the public crisis. In the future, longitudinal studies can be conducted by Big Data and Blockchain to explore the dynamics and persistence of interpersonal trust.

The third is the study on the establishment and action mechanism of interpersonal trust from the micro perspective. fDMI is conducive to exploring the microcosm of the establishment of interpersonal trust. Medical imaging can be further deployed to explore the rapid establishment, restoration and propagation mechanism of interpersonal trust in the context of crisis in the future.

Author Contributions: Conceptualization, R.L. and B.J.; methodology, R.L.; software, B.J.; investigation, R.L.; data curation, B.J.; writing—original draft preparation, B.J.; writing—review and editing, R.L.; supervision, R.L.; project administration, R.L. All authors have read and agreed to the published version of the manuscript.

Funding: This research received no external funding.

Institutional Review Board Statement: Not applicable.

Informed Consent Statement: Not applicable.

Data Availability Statement: The original data comes from WoS, and the processed data can be obtained by email to the author.

Acknowledgments: The author would like to thank everyone who provided physical and mental support for this study.

Conflicts of Interest: The author declares no conflict of interest.

\section{References}

1. Deutsch, M. Trust and Suspicion. J. Confl. Resolut. 1958, 2, 265-279. [CrossRef]

2. Rotter, J.B. A new scale for the measurement of interpersonal trust. J. Pers. 1967, 35, 651-665. [CrossRef]

3. Almakaeva, A.; Welzel, C.; Ponarin, E. Human Empowerment and Trust in Strangers: The Multilevel Evidence. Soc. Indic. Res. 2017, 139, 923-962. [CrossRef]

4. Kramer, R.M.; Lewicki, R.J. Repairing and enhancing trust: Approaches to reducing organizational trust deficits. Acad. Manag. Ann. 2010, 4, 245-277. [CrossRef]

5. Chen, Y.; Liang, C.; Cai, D. Understanding WeChat users' behavior of sharing social crisis information. Int. J. Hum. Comput Interact. 2018, 34, 356-366. [CrossRef]

6. Zhao, D.; Hu, W. Determinants of public trust in government: Empirical evidence from urban China. Int. Rev. Adm. Sci. 2017, 83, 358-377. [CrossRef]

7. Dinesen, P.T.; Schaeffer, M.; Sønderskov, K.M. Ethnic diversity and social trust: A narrative and meta-analytical review. Annu. Rev. Polit. Sci. 2020, 23, 441-465. [CrossRef] 
8. Chan, R.K. Tackling COVID-19 risk in Hong Kong: Examining distrust, compliance and risk management. Curr. Sociol. 2021, 0011392121990026. [CrossRef]

9. Kiani Mavi, R.; Gengatharen, D.; Kiani Mavi, N.; Hughes, R.; Campbell, A.; Yates, R. Sustainability in Construction Projects: A Systematic Literature Review. Sustainability 2021, 13, 1932. [CrossRef]

10. Zhang, J.; Cenci, J.; Becue, V.; Koutra, S.; Ioakimidis, C.S. Recent evolution of research on industrial heritage in Western Europe and China based on bibliometric analysis. Sustainability 2020, 12, 5348. [CrossRef]

11. Mayer, R.C.; Davis, J.H.; Schoorman, F.D. An integrative model of organizational trust. Acad. Manag. Rev. 1995, 20, 709-734 [CrossRef]

12. Putnam, R.D.; Leonardi, D.R. Making democracy work: Civic traditions in modern Italy. Contemp. Sociol. 1994, $26,306-308$.

13. Lewicki, R.J.; Bunker, B.B. Developing and maintaining trust in work relationships. Organ. Front. Front. Theory Res. 1996, 114, 139.

14. Rousseau, D.M.; Sitkin, S.B.; Burt, R.S.; Camerer, C. Not so different after all: A cross-discipline view of trust. Acad. Manag. Rev. 1998, 23, 393-404. [CrossRef]

15. Dirks, K.T.; Ferrin, D.L. Trust in leadership: Meta-analytic findings and implications for research and practice. J. Appl. Psychol. 2002, 87, 611. [CrossRef] [PubMed]

16. Kramer, R.M. Trust and distrust in organizations: Emerging perspectives, enduring questions. Annu. Rev. Psychol. 1999, 50, 569-598. [CrossRef] [PubMed]

17. McKnight, D.H.; Choudhury, V.; Kacmar, C. Developing and validating trust measures for e-commerce: An integrative typology. Inf. Syst. Res. 2002, 13, 334-359. [CrossRef]

18. McAllister, D.J. Affect-and cognition-based trust as foundations for interpersonal cooperation in organizations. Acad. Manag. J 1995, 38, 24-59.

19. Zaheer, A.; McEvily, B.; Perrone, V. Does trust matter? Exploring the effects of interorganizational and interpersonal trust on performance. Organ. Sci. 1998, 9, 141-159. [CrossRef]

20. Williamson, O.E. Calculativeness, trust, and economic organization. J. Law Econ. 1993, 36, 453-486. [CrossRef]

21. Yamagishi, T.; Yamagishi, M. Trust and commitment in the United States and Japan. Motiv. Emot. 1994, 18, 129-166. [CrossRef]

22. Coleman, J.S. Foundations of Social Theory; Harvard University Press: Cambridge, MA, USA, 1994.

23. Luhmann, N. Trust and Power; John Wiley: New York, NY, USA, 1979.

24. Gefen, D. Reflections on the dimensions of trust and trustworthiness among online consumers. ACM SIGMIS Database DATABASE Adv. Inf. Syst. 2002, 33, 38-53. [CrossRef]

25. Fukuyama, F. Trust: The Social Virtues and the Creation of Prosperity; Free Press: New York, NY, USA, 1995.

26. Lewis, J.D.; Weigert, A. Trust as a social reality. Soc. Forces 1985, 63, 967-985. [CrossRef]

27. Butler, J.K., Jr. Toward understanding and measuring conditions of trust: Evolution of a conditions of trust inventory. J. Manag. 1991, 17, 643-663. [CrossRef]

28. Hardin, R. The street-level epistemology of trust. Polit. Soc. 1993, 21, 505-529. [CrossRef]

29. Ye, F.; Song, Z.Q. A New Method to Identify the Boundary Between High- and Low-Frequency Words in Corpus Based on Zipf's Law: A Case Study of Scientometrics. J. China Soc. Sci. Inf. 2013, 32, 1196-1203.

30. Lankton, N.K.; Mcknight, D.H. What Does it Mean to Trust Facebook? Examining Technology and Interpersonal Trust Beliefs. ACM Sigmis. Database 2011, 42, 32-54. [CrossRef]

31. Nudelman, G.; Nadler, A. The effect of apology on forgiveness: Belief in a just world as a moderator. Pers. Individ. Differ. 2017, 116, 191-200. [CrossRef]

32. Ishiyama, J.; Martinez, M.; Ozsut, M. Do “Resource-Cursed States" Have Lower Levels of Social and Institutional Trust? Evidence from Africa and Latin America. Soc. Sci. Quart. 2018, 99, 872-894. [CrossRef]

33. Bulińska-Stangrecka, H.; Bagieńska, A. HR practices for supporting interpersonal trust and its consequences for team collaboration and innovation. Sustainability 2019, 11, 4423. [CrossRef]

34. Bianchini, G.E.; Navia, P.; Cuico, P.C. Qué tanto Influye la Ideología en la Confianza que Depositan los Chilenos en Otros? Dados 2019, 62. [CrossRef]

35. Park, S.; Kim, E.J. Fostering organizational learning through leadership and knowledge sharing. J. Knowl. Manag. 2018, 22, $1408-1423$.

36. Olaisen, J.; Revang, O. Working smarter and greener: Collaborative knowledge sharing in virtual global project teams. Int. J. Inform. Manag. 2017, 37, 1441-1448. [CrossRef]

37. Burt, R.S.; Bian, Y.; Opper, S. More or less guanxi: Trust is $60 \%$ network context, $10 \%$ individual difference. Soc. Netw. 2018, 54 , 12-25. [CrossRef]

38. Tong, C.K.; Yong, P.K. Guanxi bases, xinyong and Chinese business networks. In Chinese Business; Springer: Singapore, 2014; pp. 41-61.

39. Gundelach, B.; Traunmüller, R. Beyond generalised trust: Norms of reciprocity as an alternative form of social capital in an assimilationist integration regime. Political Stud. 2014, 62, 596-617. [CrossRef]

40. Lins, K.V.; Servaes, H.; Tamayo, A. Social capital, trust, and firm performance: The value of corporate social responsibility during the financial crisis. J. Financ. 2017, 72, 1785-1824. [CrossRef] 
41. Ommen, O.; Thuem, S.; Pfaff, H.; Janssen, C. The relationship between social support, shared decision-making and patient's trust in doctors: A cross-sectional survey of 2197 inpatients using the Cologne Patient Questionnaire. Int. J. Public Health 2011, 56 , 319-327. [CrossRef]

42. Cassar, A.; Healy, A.; Von Kessler, C. Trust, risk, and time preferences after a natural disaster: Experimental evidence from Thailand. World Dev. 2017, 94, 90-105. [CrossRef]

43. Brown, H.; Marí Sáez, A. Ebola separations: Trust, crisis, and 'social distancing'in West Africa. J. R. Anthropol. Inst. 2021, 27, 9-29. [CrossRef]

44. Ward, P.R.; Mamerow, L.; Meyer, S.B. Interpersonal trust across six Asia-Pacific countries: Testing and extending the 'high trust society'and 'low trust society'theory. PLoS ONE 2014, 9, e95555.

45. Fischer, S.; Hyder, S.; Walker, A. The effect of employee affective and cognitive trust in leadership on organisational citizenship behaviour and organisational commitment: Meta-analytic findings and implications for trust research. Aust. J. Manag. 2020, 45, 662-679. [CrossRef]

46. Engelmann, J.B.; Meyer, F.; Ruff, C.C.; Fehr, E. The neural circuitry of affect-induced distortions of trust. Sci. Adv. 2019, 5, eaau3413. [CrossRef] [PubMed]

47. Dubey, R.; Gunasekaran, A.; Childe, S.J.; Roubaud, D.; Wamba, S.F.; Giannakis, M.; Foropon, C. Big data analytics and organizational culture as complements to swift trust and collaborative performance in the humanitarian supply chain. Int. J. Prod. Econ. 2019, 210, 120-136. [CrossRef]

48. Kong, D.T.; Dirks, K.T.; Ferrin, D.L. Interpersonal trust within negotiations: Meta-analytic evidence, critical contingencies, and directions for future research. Acad. Manag. J. 2014, 57, 1235-1255. [CrossRef]

49. Dubey, R.; Gunasekaran, A.; Bryde, D.J.; Dwivedi, Y.K.; Papadopoulos, T. Blockchain technology for enhancing swift-trust, collaboration and resilience within a humanitarian supply chain setting. Int. J. Prod. Res. 2020, 58, 3381-3398. [CrossRef] 